\title{
Characterization of Electrochromic Properties of Polyaniline Thin Films Electropolymerized in $\mathrm{H}_{2} \mathrm{SO}_{4}$ Solution
}

\author{
Dang Hai Ninh1, Tran Thi Thao1, Pham Duy Long', Nguyen Nang Dinh1 \\ ${ }^{1}$ University of Engineering and Technology, Vietnam National University Hanoi, Hanoi, Vietnam \\ ${ }^{2}$ Institute of Materials Science, Vietnamese Academy of Science and Technology, Hanoi, Vietnam \\ Email: dinhnn@vnu.edu.vn
}

Received 3 November 2015; accepted 8 January 2016; published 12 January 2016

Copyright (C) 2016 by authors and Scientific Research Publishing Inc.

This work is licensed under the Creative Commons Attribution International License (CC BY). http://creativecommons.org/licenses/by/4.0/

cC) (i) Open Access

\begin{abstract}
Polyaniline (PANI) onto indium-doped tin-oxide (ITO)-coated glass samples were prepared by electroopolymerization in $0.5 \mathrm{M} \mathrm{H}_{2} \mathrm{SO}_{4}$ solution. Structure and morphology characterization of the PANI films demonstrated that the films were grown onto ITO substrates in the form of polycrystalline microbelts separated by micropores. By analysing the UV-Vis absorption spectra of the PANI films, the energy bandgap was found to be approximately $2.75 \mathrm{eV}$. The PANI/ITO films exhibited a good reversible electrochromic display (ECD) performance when cycled in $0.1 \mathrm{M} \mathrm{LiClO}_{4}+$ pro-pylene carbonate. The response time of the ECD coloration was found to be as small as $15 \mathrm{~s}$ and the coloration efficiency was found to be $8.85 \mathrm{~cm}^{2} \times \mathrm{C}^{-1}$. After 100 cycles of the ECD performance, the cyclic voltammetry curve of the working electrode maintained unchanged. This demonstrates that the electropolymerized PANI films can be served as a good candidate for ECD applications, taking advantage of their excellent properties in terms of chemical stability.
\end{abstract}

\section{Keywords}

Polyaniline, Thin Films, UV-Vis Absorption, Electrochromic Property

\section{Introduction}

The properties of the electrochromic display (ECD) of almost all the transition-metals oxides have been investigated [1]. These oxides films can be colored anodically (Ir, Ni) or cathodically (W, Ti). Together with inorganic materials, conducting polymers have also been intensively studied for polymer electrochromic devices (PECDs) [2]. Besides, conjugate polymers have been used for other applications such as polymer conductors [3], elec-

How to cite this paper: Ninh, D.H., Thao, T.T., Long, P.D. and Dinh, N.N. (2016) Characterization of Electrochromic Properties of Polyaniline Thin Films Electropolymerized in $\mathrm{H}_{2} \mathrm{SO}_{4}$ Solution. Open Journal of Organic Polymer Materials, 6, 30-37. http://dx.doi.org/10.4236/ojopm.2016.61004 
tronic components [4] [5], organic light-emitting diodes (OLED) [6] and solar cells (OSC) [7]. This is because conjugate polymers exhibit valuable advantages, such as thermal stability, low cost and easy preparation. Among the PECD materials, polyaniline (PANI) is widely used. There are some works focusing on PANI/ITO thin films for electrochemical supercapacitor applications. For example, the PANI films with different thicknesses and nanostructures were synthesized onto ITO substrates by using an electrodeposition technique using selenious [8] or sulfuric acid [9]. PANI has three main stable oxidation states: the fully reduced leucoemeraldine form, the $50 \%$ oxidized emeraldine form, and the fully oxidized pernigraniline form. Each of these states can exist in the form of its base or in the form of its protonated salt by subtracting or adding protons which does not modify its oxidation state. So that PANI is a multi-colour electrochromic material, such as transparent yellow for the leucoemeraldine form, green for the emeraldine salt form (ES), blue for the emeraldine base form (EB), and black for the pernigraniline form. With doping, the conductivity of PANI can reach a value from $10^{-10}$ to 10 $\Omega^{-1} \cdot \mathrm{cm}^{-1}[10]$. The conductivity of PANI films mainly depends on the oxidation state, $\mathrm{pH}$ of the electrolyte and the type of dopant used for protonation [11]. PANI exhibits reverse electrochromic performance; it is able to switch from a transparent yellow state to a green one, according to reduction and oxidation processes [12].

In this work, we report the investigation results on the structural, optical, morphological and electrochromic properties of PANI thin films prepared by electropolymerization in $\mathrm{H}_{2} \mathrm{SO}_{4}$ solution.

\section{Experimental}

Analytical reagent grade aniline and sulfuric acid $\left(\mathrm{H}_{2} \mathrm{SO}_{4}\right)$ were used for the electropolymerization of PANI in an aqueous solution. $10 \Omega$ indium-doped tin-oxide (ITO)-coated glass was used for substrates. Electrochemical processes were carried-out by using an AUTOLAB-Potentiostat PGS-30 electrochemical unit in a standard three-electrode cell, where PANI/ITO served as working electrode (WE), Ag/AgCl as reference electrode (AAE) and a platinum grid as counter electrode (CE). The electrolyte used for electropolymerization was composed of aqueous solution of $0.1 \mathrm{M}$ aniline and $0.5 \mathrm{M}$ dopant sulfuric acid. PANI thin films were electropolymerized by sweeping the potential between $-0.20 \mathrm{~V}$ and $+1.20 \mathrm{~V} / \mathrm{AAE}$ for 10 numbers of scans. All the prepartion experiments were performed at room temperature without stirring. The as-deposited PANI films were dried in gaseous nitrogen and kept in a clean glove-box until use for further properties characterization. The electrochromic performance was carried out on the same PGS-30 potentiostat, using $0.1 \mathrm{M} \mathrm{LiClO}_{4}+$ propylene carbonate $\left(\mathrm{LiClO}_{4}\right.$ + PC) solution for electrolyte.

The surface morphology was studied using a Hitachi "S-4800" field-emission scanning electron microscope (FE-SEM). X-ray diffraction analysis (XRD) was done on a Brucker “Advance-8D” X-ray diffractometer. Optical absorption measurements were carried using a JASCO ultraviolet-visible-near infrared (UV-Vis-NIR) "V-570" spectrophotometer. By using this photospectrometer, in situ transmittance spectra of PANI/ITO in $\mathrm{LiClO}_{4}+\mathrm{PC}$ vs. polarized potentials were recorded on the PANI/ITO films as the WE mounted into a modified electrochemical cell which was placed under the pathway of the laser beam. All measurements were executed at room temperature.

\section{Results and Discussion}

The PANI films electropolymerization process in $\mathrm{H}_{2} \mathrm{SO}_{4}$ solution was strongly dependent on both the concentration of $\mathrm{H}_{2} \mathrm{SO}_{4}$, the scan rate and the range of the potentials used. Figure 1 shows typical cyclic voltammograms (CVs) of best samples obtained in the PANI films electropolymerization processes. The electrolyte contains 0.1 $\mathrm{M}$ aniline monomer with $0.5 \mathrm{M}$ concentration of $\mathrm{H}_{2} \mathrm{SO}_{4}$. The CVs were recorded for 10 successive cycles at a scan rate of $50 \mathrm{mV} / \mathrm{s}$ for potential range from -0.20 to $+1.20 \mathrm{~V} / \mathrm{AAE}$. A high redox peak appeared at $\sim 1.15$ V/AAE for the first cycle of CV. According to report in [13], this peak is associated with the oxidation of aniline oligomers. We also observed the decrease in growth rate upon repeating the potential cycle, as in [14] the authors explained this phenomenon by the poor electrochemical activity of the PANI film formed on the electrode surface due to the difficulty in maintaining the protonated and doped structures of the polymers. The successive anodic scan shows the presence of three distinct peaks which are marked as "a", "b" and "c" attributing to the oxidation of fully reduced form of PANI (leucoemeridine) to its polaron form, oxidation of intermediate species, and final transition from delocalized polaronic state to bipolaron or quinoid form, respectively [14]. The potential of peak "a" is shifted toward higher anodic side with successive scanning could be due to the degradation of 


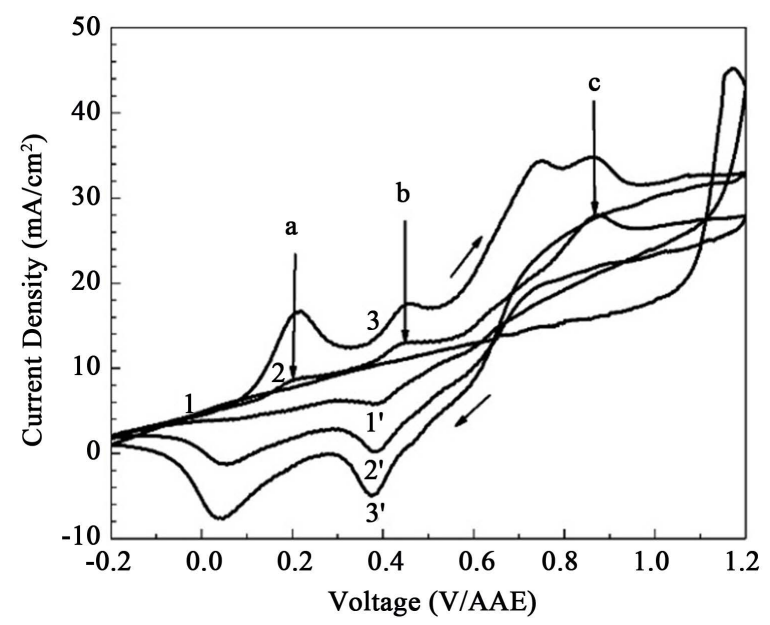

Figure 1. CV curves of PANI/ITO films made by electropolimerization in $0.1 \mathrm{M}$ aniline and $0.5 \mathrm{M} \mathrm{H}_{2} \mathrm{SO}_{4}$ solution by $\mathrm{CV}$-cycling with a rate of $50 \mathrm{mV} / \mathrm{s}$ : (1-1') - First cycle; (2-2') —-5-th cycle; and (3-3')-10-th cycle.

PANI deposited in the previous scan. After completing 10 cycles, greenish-colored thin films were deposited which confirms the formation of ES of PANI. The thickness (d) of the film measured on a profilometer (Deltak $6 \mathrm{M}$ ) was about $200 \mathrm{~nm}$.

The crystalline structure of the PANI/ITO sample was checked by using an accessory for films with a small angle of the X-ray incident beam. For such a thin PANI film, some XRD patterns of the ITO substrate also appeared. Thus the XRD diagram shows both the diffraction peaks of ITO substrate and PANI film.

Indeed, in Figure 2 there are four diffraction peaks revealed which are quite consistent with the peaks of the atomic distances for a crystalline phase of $\mathrm{In}_{2} \mathrm{O}_{3}$ - the host lattice of the ITO. Two intense bands observed approximately at $2 \theta$ of $15.5^{\circ}$ and $24.3^{\circ}$ confirmed the synthesis of ES of PANI [15].

The crystallinity of PANI thin film deposited in the presence of $0.5 \mathrm{M} \mathrm{H}_{2} \mathrm{SO}_{4}$ was found to be improved due to the change in surface morphology and compactness. The value of full width half maximum calculated for the peak at $2 \theta=24.3^{\circ}$ was of as small as $0.06^{\circ}$. Indeed, we observed the change in the morphology as well as compactness for the PANI film deposited in $0.5 \mathrm{M}$ concentration of $\mathrm{H}_{2} \mathrm{SO}_{4}$ by means of FE-SEM micrographs.

The morphology of the PANI films electropolymerized in the presence of $0.5 \mathrm{M}$ concentration of dopant acid is shown in Figure 3. The microbelts of diameter approximately $200 \mathrm{~nm}$ are formed. The film was compact and fully deposited all over the substrate, this could be explained due to the high current flow from electrolyte to the electrode. Between the microbelts there are numerous pores served as the microcanals that constitute a factor favouring ions faster insert (extract) in (out of) the PANI films. This may improve both the response time and the performance efficiency of the electrochromic coloration.

The optical absorption spectra are often used to investigate the oxidation state of PANI. Figure 4 shows the optical absorption spectra of a PANI film obtained during the electropolymerization at $0.5 \mathrm{M}$ concentration of $0.5 \mathrm{M} \mathrm{H}_{2} \mathrm{SO}_{4}$ at a fixed scan rate of $50 \mathrm{mV} / \mathrm{s}$. Three strong absorption peaks attributed at 328, 420 and $789 \mathrm{~nm}$ correspond to the formation of PANI in ES form. The peak observed at $317 \mathrm{~nm}$ is attributed to the transition of electrons from the highest occupied molecular orbital (HUMO) to the lowest unoccupied molecular orbital (LUMO) which is related to the $\pi-\pi^{*}$ electronic transition [16]. The other two absorption peaks observed at about 320 and $789 \mathrm{~nm}$ are associated with the polaron and bipolaron band transitions of PANI, respectively [16]. It is known that the polaron and bipolaron are the charge carriers in conducting PANI.

UV-Vis data can be used to estimate the energy bandgap, $E_{g}$, of the PANI films by using the following expression [17].

$$
\alpha h v=A\left(h v-E_{g}\right)^{n}
$$

where $h$ is Planck's constant, $v$ is the frequency of the incident UV-Vis radiation, $A$ is a constant and $n$ is $1 / 2$ for direct band semiconductors and 2 for indirect band gap semiconductors. As expected, best fits were obtained for $n=2$ (indirect band). 


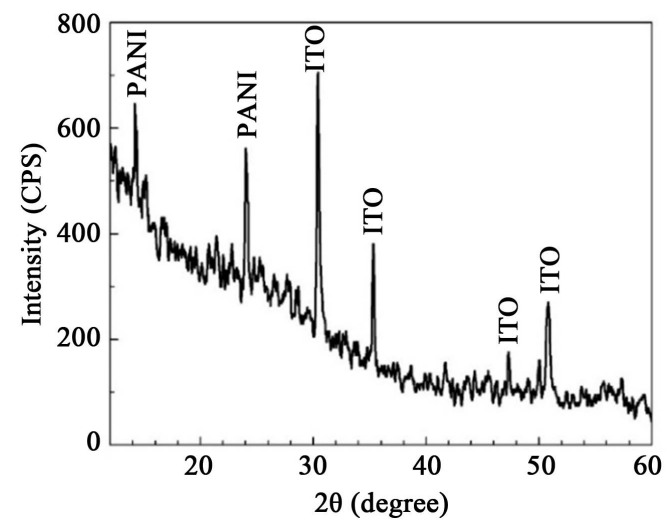

Figure 2. XRD pattern for a PANI thin film electropolymerized in the presence of $0.5 \mathrm{M}$ concentration of $\mathrm{H}_{2} \mathrm{SO}_{4} ; \mathrm{d} \sim 200 \mathrm{~nm}$.

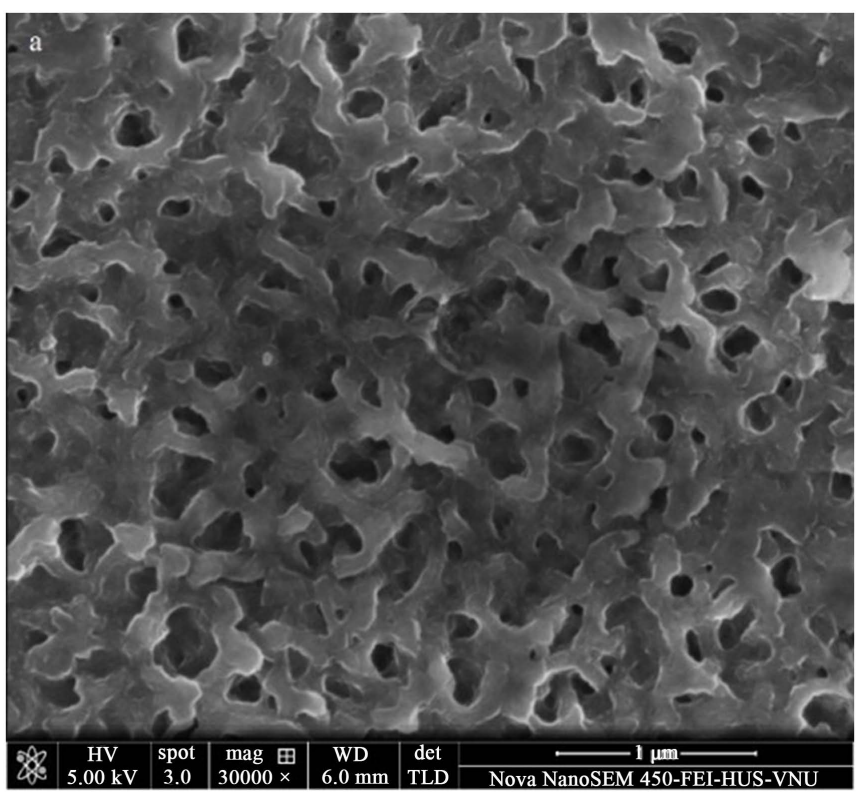

Figure 3. SEM of as-deposited PANI thin film $(\mathrm{d} \sim 200 \mathrm{~nm})$ onto ITO substrate in $\mathrm{H}_{2} \mathrm{SO}_{4}$ solution.

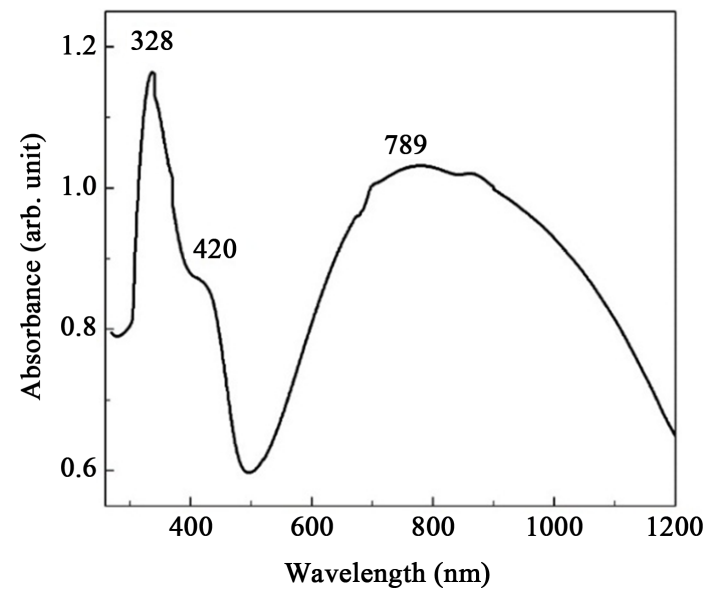

Figure 4. Absorption spectra of a PANI/ITO thin film electropolymerized in the presence of $0.5 \mathrm{M}$ concentration of $\mathrm{H}_{2} \mathrm{SO}_{4}$. 
A graph is plotted between $(\alpha \mathrm{h} v)^{2}$ or the square of $(\alpha \mathrm{h} v)$ and $\alpha \mathrm{h} v$ (as abscissa), a straight line is obtained. From the extrapolation of the straight line to $(\alpha h v)^{2}=0$ axis one can determine the bandgap of the investigated sample. Thus from our experiments, the energy gap of PANI films deposited by electropolymerization in the presence of $0.5 \mathrm{M}$ concentration of $\mathrm{H}_{2} \mathrm{SO}_{4}$ was found to be of approximately $2.75 \mathrm{eV}$ (Figure 5). This value is comparable to that for PANI prepared by redox polymerization of aniline using ammonium persulphate, $\left(\mathrm{NH}_{4}\right)_{2} \mathrm{~S}_{2} \mathrm{O}_{\mathrm{x}}$, as dopant [18].

Figure 6 shows the cyclic voltammetry (CV) curve in $0.1 \mathrm{M} \mathrm{LiClO}_{4}+\mathrm{PC}$ of a PANI/ITO film, the CV spectra being recorded at the fifth cycle. Such a curve is typical of films prepared in our studies with a thickness of $200 \mathrm{~nm}$. From this figure one can see the symmetrical shape of the CV spectra toward the coordinates $(\mathrm{x}=0.5$; $\mathrm{y}$ $=0.2$ ). In the positive sweep direction (PSD) a peak of the anodic current density corresponding to a value of ca. $0.64 \mathrm{~mA}$ was obtained at a potential of $0.75 \mathrm{~V} / \mathrm{AAE}$. A negative value $(-0.22 \mathrm{~mA})$ of the peak in the negative sweep direction (NSD) was obtained at a potential of 0.35 V/AAE. The symmetrical CV proves a good reversibility of the processes of $\left(\mathrm{ClO}_{4}^{-}\right)$ion insertion/extraction from the electrolyte into /out of the working electrode (PANI/ITO). During the oxidation, the $\mathrm{ClO}_{4}^{-}$ions of $\mathrm{LiClO}_{4} / \mathrm{PC}$ electrolyte solution were injected to the PANI thin film. During the reduction, the $\mathrm{ClO}_{4}^{-}$ions of $\mathrm{LiClO}_{4} / \mathrm{PC}$ electrolyte solution were excluded the PANI thin film. The overall reaction, involving ion insertion (extraction) in (out of) the PANI film to balance the charge, can be represented as follows [19]:

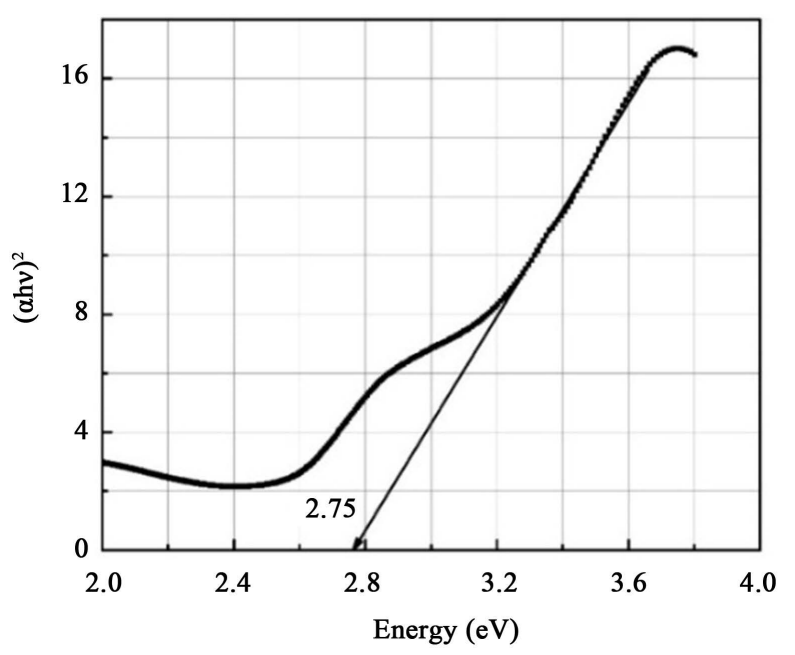

Figure 5. Bandgap determination of PANI film electropolymerized in $0.5 \mathrm{M} \mathrm{H}_{2} \mathrm{SO}_{4}$ solution.

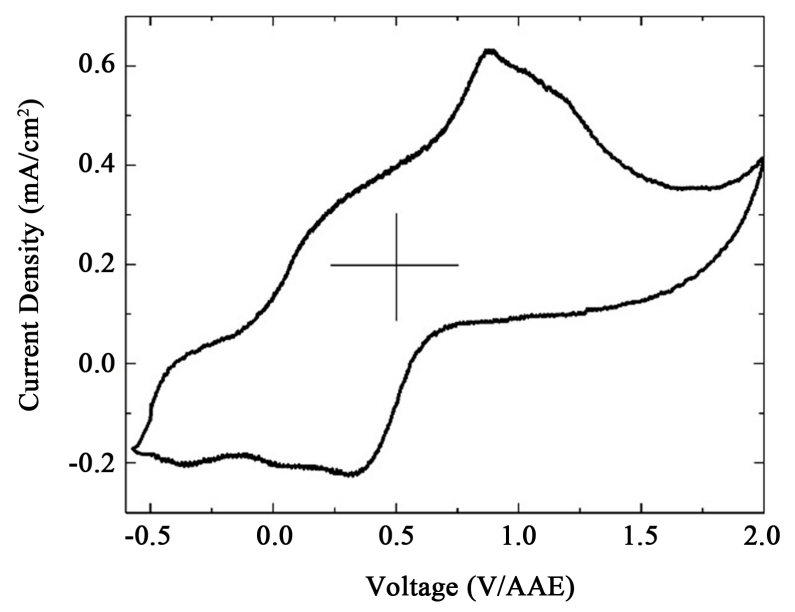

Figure 6. Cyclic voltammetry of PANI/ITO/Glass in $0.1 \mathrm{M} \mathrm{LiClO}_{4}+$ $\mathrm{PC}$; the scanning rate is of $50 \mathrm{mV} / \mathrm{s}$. 


$$
\begin{aligned}
& (\mathrm{ANI}) \mathrm{n}+\mathrm{ny}\left(\mathrm{ClO}_{4}^{-}\right) \leftrightarrow\left[(\mathrm{ANI}+)+\mathrm{y}\left(\mathrm{ClO}_{4}^{-}\right)\right] \mathrm{n}+\mathrm{nye}^{-} \\
& (\text {Light Green }) \\
& \quad \text { (Green })
\end{aligned}
$$

where $n$ is the number of repeated units and y is the stoichiometric number of the counter ion.

To study the electrochromic performance, a device with the structure of Glass/ITO/Electrolyte/PANI/ITO/ Glass (abbreviated to Pani-ECD) was prepared.

The $\mathbf{L i C l O}_{4}+\mathbf{P C}$ electrolyte was dropped onto the working electrode with a $1 \times 1 \mathrm{~cm}^{2}$ active area and thickness of the electrolyte was fixed at the same value of the thickness of the Scotch tape (i.e. $~ 50 \mu \mathrm{m}$ ). The PANI/ ITO and ITO/Glass electrodes of the device were connected to WE and CE of the PGS-30 with a polarized potential of $-0.5 \mathrm{~V}$ and $+1.5 \mathrm{~V}$. For the device with a $200 \mathrm{~nm}$-thick PANI film, the in situ transmission spectra obtained during electrochromic performance are given in Figure 7. The completely coloured (curve "a") and bleached (curve "b") states occurred considerably fast, after approximately $15 \mathrm{sec}$ and $5 \mathrm{sec}$, respectively. The PANI/ITO has the maximum optical transmittance variation, $\Delta T$ (\%), which was larger $40 \%$ at $530 \mathrm{~nm}$.

To evaluate the electrochromic coloration efficiency $(\eta)$ we used a well-known expression relating the efficiency with the optical density, consequently the transmittances of coloration $\left(T_{c}\right)$ and bleaching states $\left(T_{b}\right)$, and the insertion charge $(Q)$ are as follows [20]:

$$
\eta=\frac{\Delta O D}{Q}=\frac{1}{Q} \ln \left(\frac{T_{b}}{T_{c}}\right)
$$

In our experiments $Q=0.14 \mathrm{mC} \times \mathrm{cm}^{-2}$. At a wavelength of $530 \mathrm{~nm}, T_{b}=62 \%$ and $T_{c}=18 \%$, thus the coloration efficiency was found to be of $\sim 8.85 \mathrm{~cm}^{2} \times \mathrm{C}^{-1}$. In the visible range of wavelengths all the values of $\eta$ found are comparable to those for PANI/ITO/Glass that was electropolymerized in $2 \mathrm{M} \mathrm{HCl}$ solution [21] and a little higher than those for PANI/ITO/Glass prepared by electrochemistry [22].

To investigate the durability of the PANI films, a PANI/ITO/Glass of $1.0 \mathrm{~cm}^{2}$ in size was measured in $0.1 \mathrm{M}$ $\mathrm{LiClO}_{4}+$ PC. The scanning potentials range was from -0.5 to $+2.0 \mathrm{~V} / \mathrm{AAE}$ and a number of the cycles was chosen as large as 100 cycles. The CV curves recorded from the first to hundredth cycle are shown in Figure 8. From the fifth to tenth cycle, in both the PSD and NSD the current density in absolute value was found to slightly increase; it then slowly decreased. After 100 cycles, the CV curve was maintained unchanged and the current density of the CV peak lowered to a value of $\sim 90 \%$ of the initial value (at the saturation coloration state, i.e. at the tenth cycle of the cyclic voltammetry). This demonstrates that the $\mathrm{ClO}_{4}^{-}$insertion (extraction) into (out of) the porous PANI films could be easily performed. For the $\mathrm{TiO}_{2} / \mathrm{ITO}$ films deposited by the sol-gel technique, the time to get a saturated state of coloration was as large as $45 \mathrm{~min}$ for a sample size of $1 \mathrm{~cm}^{2}$ [23]. In the

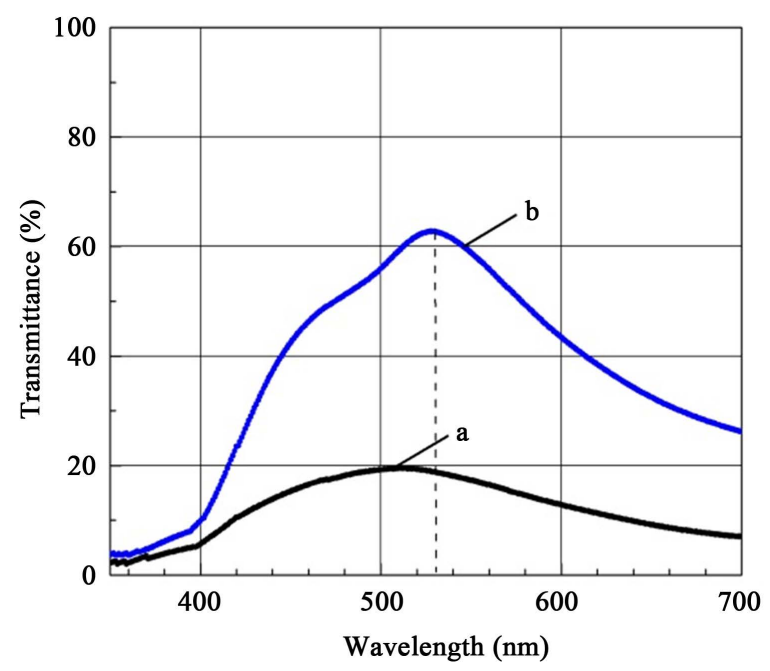

Figure 7. Transmittances of the Pani-ECD device. The oxidizing potential and reducing potential were set $+1.0 \mathrm{~V}$ and $-0.5 \mathrm{~V}$, respectively. Curve "a" is the colored state and curve "b" is bleached state. 


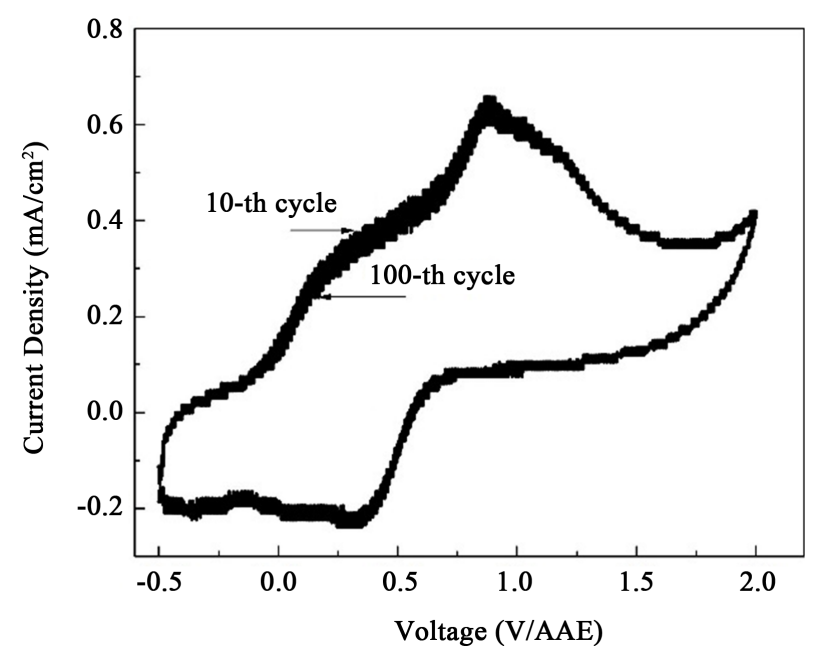

Figure 8. Testing of the durability of an ECD device with a structure of Glass/ITO/PANI/LiClO 4 + PC/ITO/Glass; the scanning rate is of $50 \mathrm{mV} / \mathrm{s}$.

present work, the PANI/ITO was coloured very rapidly for a sample of the same size. The saturated coloration was reached about $15 \mathrm{sec}$ after a negative potential of $-1.20 \mathrm{~V} / \mathrm{AAE}$ was applied to the WE in the $0.1 \mathrm{M} \mathrm{LiClO}_{4}$ + PC electrolyte. A deep green colour was observed in the coloration state and a light green (bleached state) was obtained after less than 5 sec.

\section{Conclusions}

PANI/ITO/Glass thin films were electropolymerized in the presence of $0.5 \mathrm{M}$ concentration of $\mathrm{H}_{2} \mathrm{SO}_{4}$. The PANI films were formed in polycrystalline microbelts separated each other by micropores. From UV-Vis data of the films, the energy bandgap of the PANI films was estimated, as approximately $2.75 \mathrm{eV}$. Electrochromic performance of the Pani-ECD device was carried out in $0.1 \mathrm{M} \mathrm{LiClO}_{4}+$ propylene carbonate electrolyte, and a good reversible coloration and bleaching process was obtained. The response time and the coloration efficiency of the coloration of PANI/ITO films were found to be $15 \mathrm{~s}$ and $8.85 \mathrm{~cm}^{2} \times \mathrm{C}^{-1}$, respectively.

The results of the ECD performance for 100 cycles showed that electropolymerized PANI thin films possess a long durability. Thus polyaniline thin films can be served as a good candidate for ECD applications, taking advantage of their excellent properties in terms of chemical stability.

\section{Acknowledgements}

This research is funded by Vietnam National Foundation for Science and Technology (NAFOSTED) under grant number 103.02-2013.39.

\section{References}

[1] Granqvist, C.G. (1995) Handbook of Inorganic Electrochromic Materials. Elsevier, Amsterdam.

[2] Yildirim, A., Tarkuc, S. and Toppare, M.A.L. (2008) Syntheses of Electroactive Layers Based on Functionalized Anthracene for Electrochromic Applications. Electrochimica Acta, 53, 4875-4882. http://dx.doi.org/10.1016/j.electacta.2008.02.026

[3] Crispin, X., Jakobsson, F.L.E., Crispin, A., Grim, P.C.M., Andersson, P., Volodin, A., van Haesendonck, C., Van der Auweraer, M., Salaneck, W.R. and Berggren, M. (2006) The Origin of the High Conductivity of Poly(3,4-ethylenedioxy-thiophene)-poly(styrenesulfonate) (PEDOT-PSS) Plastic Electrodes. Chemistry of Materials, 18, 4354-4360. http://dx.doi.org/10.1021/cm061032+

[4] Sirringhaus, H., Kawase, T., Friend, R.H., Shimoda, T., Inbasekaran, M., Wu, W. and Woo, E.P. (2000) High-Resolution Inkjet Printing of All-Polymer Transistor Circuits. Science, 290, 2123-2126. http://dx.doi.org/10.1126/science.290.5499.2123

[5] Katz, H.E. and Huang, J. (2009) Thin-Film Organic Electronic Devices. Annual Review of Materials Research, 39, 
71-92. http://dx.doi.org/10.1146/annurev-matsci-082908-145433

[6] Parker, I.D. (1994) Carrier Tunneling and Device Characteristics in Polymer Light-Emitting Diodes. Journal of Applied Physics, 75, 1656-1666. http://dx.doi.org/10.1063/1.356350

[7] McCullough, R.D. and Ewbank, P.C. (1998) Regioregular, Head-to-Tail Coupled Poly(3-alkylthiophene) and Its Derivatives. In: Skotheim, T.A., Ed., Handbook of Conducting Polymers, Marcel Dekker, New York, Chapter 9, 225-258.

[8] Amarnath, C.A., Chang, J., Lee, J., Kim, D.Y., Mane, R.S., Han, S.-H. and Sohn, D. (2008) Direct Polymerized Polyaniline Nanostructures on Modified Indium-Tin Oxide Surface for Electrochemical Supercapacitors. Electrochemical and Solid-State Letters, 11/10, A167-A169. http://dx.doi.org/10.1149/1.2958086

[9] Inamdar, A.I., Kim, Y.S., Sohn, J.S., Im, H., Kim, H., Kim, D.-Y., Kalubarme, R.S. and Park, C.J. (2011) Supercapacitive Characteristics of Electrodeposited Polyaniline Thin Films Grown on Indium-Doped Tin-Oxide Substrates. JKPS, 59, 145-149. http://dx.doi.org/10.3938/jkps.59.145

[10] Salavagione, H.J., Sanchis, C. and Moralln, E. (2007) Friendly Conditions Synthesis of Platinum Nanoparticles Supported on a Con-Ducting Polymer: Methanol Electrooxidation. Journal of Physical Chemistry C, 111, 12454-12460. http://dx.doi.org/10.1021/jp071037+

[11] Focke, W.W., Wnek, G.E. and Wei, Y. (1987) Influence of Oxidation State, pH, and Counterion on the Conductivity of Polyaniline. The Journal of Physical Chemistry, 91, 5813-5818. http://dx.doi.org/10.1021/j100306a059

[12] Ashwini, B., Priyanka, U.L., Mahapatra, S.K., Kulkarni, S.K. and Chaure, N.B. (2014) Electropolymerization of Polyaniline Thin Films. High Performance Polymers, 26, 641-646. http://dx.doi.org/10.1177/0954008314538081

[13] Hong, S.Y. and Park, S.M. (2005) Electrochemistry of Conductive Polymers 36. pH Dependence of Polyaniline Conductivities Studied by Current-Sensing Atomic Force Microscopy. The Journal of Physical Chemistry B, 109, 93059310. http://dx.doi.org/10.1021/jp050173g

[14] Stilwell, D.E. and Park, S.M.J. (1988) Electrochemistry of Conductive Polymers II. Electrochemical Studies on Growth Properties of Polyaniline. Journal of the Electrochemical Society, 135, 2254-2262. http://dx.doi.org/10.1149/1.2096248

[15] Chaudhari, H.K. and Kelkar, D.S. (1996) X-Ray Diffraction Study of Doped Polyaniline. Journal of Applied Polymer Science, 62, 15-18. http://dx.doi.org/10.1002/(SICI)1097-4628(19961003)62:1<15::AID-APP3>3.0.CO;2-V

[16] Abdulla, H.S. and Abbo, A.I. (2012) Optical and Electrical Properties of Thin Films of Polyaniline and Polypyrrole. International Journal of Electrochemical Science, 7, 10666-10678.

[17] Tauc, J. (1974) Amorphous and Liquid Semiconductors. Plenum, New York, 159.

[18] Joshi, G.P., Saxena, N.S., Sharma, T.P., Dixit, V. and Misra, S.C.K. (2003) Bandgap Determination of Chemically Doped Polyaniline Materials from Reflectance Measurements. Indian Journal of Pure \& Applied Physics, 41, 462-465.

[19] Shen, K.Y., Hu, C.W., Chang, L.C. and Ho, K.C. (2012) A Complementary Electrochromic Device Based on Carbon Nanotubes/Conducting Polymers. Solar Energy Materials \& Solar Cells, 98, 294-299. http://dx.doi.org/10.1016/j.solmat.2011.11.020

[20] Monk, P.M.S., Mortimer, R.J. and Rosseinsky, D.R. (1995) Electrochromism: Fundamentals and Applications. VCH, Weinheim-New York-Basel-Cambridge-Tokyo. http://dx.doi.org/10.1002/9783527615377

[21] Liu, C.Y., Chou, J.C., Liao, Y.H., Yang, C.J., Huang, C.J., Cheng, T.Y., Hu, J.E. and Chou, H.T. (2013) The Investigation of the Electrochromic Characteristics for the PANI Thin Film by Cyclic Voltammetry and Potentiostatic Method. Proceedings of the World Congress on Engineering, Vol. 2, London, 3-5 July 2013, 999-1003.

[22] Kang, J.H., Oh, Y.J., Peak, S.M., Hwang, S.J. and Choy, J.H. (2009) Electrochromic Device of PEDOT-PANI Hybrid System for Fast Response and High Optical Contrast. Solar Energy Materials \& Solar Cells, 93, 2040-2044. http://dx.doi.org/10.1016/j.solmat.2009.08.007

[23] Dinh, N.N., Oanh, N.T.T., Long, P.D., Bernard, M.C. and Hugot-Le Goff, A. (2003) Elecrochromic Properties of TiO 2 Anatase Thin Films Prepared by Dipping Sol-Gel Method. Thin Solid Films, 423, 70-76. http://dx.doi.org/10.1016/S0040-6090(02)00948-3 